\title{
Sodium-glucose cotransporter 2 inhibitors: a practical guide for the Dutch cardiologist based on real-world experience
}

\author{
K. Zwart · S. Velthuis · Y. V. Polyukhovych · A. Mosterd · L. Smidt · E. H. Serné - D. H. van Raalte · P. J. M. Elders · \\ M. L. Handoko (D) P. C. Oldenburg-Ligtenberg
}

Accepted: 29 April 2021 / Published online: 16 June 2021

(C) The Author(s) 2021

\begin{abstract}
Sodium-glucose cotransporter 2 (SGLT2) inhibitors include a relatively new class of glucoselowering drugs that reduce plasma glucose concentrations by inhibiting proximal tubular reabsorption of glucose in the kidney, while increasing its excretion in urine. Recent large randomised controlled trials have demonstrated that many of these agents reduce the occurrence of major adverse cardiovascular events, hospitalisation for heart failure, cardiovascular death and/or chronic kidney disease progression in patients with and without type 2 diabetes mellitus (DM2). Given their unique insulin-independent mode
\end{abstract}

M.L. Handoko and P.C. Oldenburg-Ligtenberg contributed equally as last author.

Supplementary Information The online version of this article (https://doi.org/10.1007/s12471-021-01580-9) contains supplementary material, which is available to authorized users.

\section{K. Zwart · L. Smidt · P. C. Oldenburg-Ligtenberg}

Department of Internal Medicine/Endocrinology, Meander Medical Centre, Amersfoort, The Netherlands

\section{S. Velthuis · A. Mosterd}

Department of Cardiology, Meander Medical Centre, Amersfoort, The Netherlands

Y. V. Polyukhovych · M. L. Handoko ( $\square)$

Department of Cardiology, Amsterdam University Medical Centers, location VU University Medical Center, Amsterdam, The Netherlands

ml.handoko@amsterdamumc.nl

\section{E. H. Serné · D. H. van Raalte}

Department of Internal Medicine/Endocrinology, Amsterdam University Medical Centers, location VU University Medical Center, Amsterdam, The Netherlands

\section{P. J. M. Elders}

Department of General Practice, Amsterdam University Medical Centers, location VU University Medical Center, Amsterdam, The Netherlands of action and favourable efficacy and adverse-event profile, SGLT2 inhibitors are promising and they offer an interesting therapeutic approach for the cardiologist to incorporate into routine practice. However, despite accumulating data supporting this class of therapy, cardiologists infrequently prescribe SGLT2 inhibitors, potentially due to a lack of familiarity with their use and the reticence to change DM medication. Here, we provide an up-to-date practical guide highlighting important elements of treatment initiation based on real-world evidence and expert opinion. We describe how to change DM medication, including insulin dosing when appropriate, and how to anticipate any adverse events based on real-world experience in patients with DM2 in the Meander Medical Centre in Amersfoort, the Netherlands. This includes a simple algorithm showing how to initiate SGLT2 inhibitor

\section{What's new?}

- Sodium-glucose cotransporter 2 (SGLT2) inhibitors include a relatively new class of glucoselowering drugs.

- Recent large randomised controlled trials have demonstrated that many of these agents reduce the occurrence of major adverse cardiovascular events, hospitalisation for heart failure, cardiovascular death, and/or chronic kidney disease progression, regardless of the presence or absence of diabetes mellitus.

- We provide an up-to-date practical guide for the cardiologist, highlighting important elements for treatment initiation based on real-world evidence and expert opinion, including a simple algorithm that shows how to initiate SGLT2 inhibitor treatment safely. 
treatment safely, while considering the consequence of the glucosuric effects of these inhibitors for the individual patient.

Keywords SGLT2 inhibitor · Cardiologist · Guide · Flowchart · Real-world evidence

\section{Introduction}

Sodium-glucose cotransporter 2 (SGLT2) inhibitors have emerged as an important new oral glucoselowering class of drugs for the management of hyperglycaemia in patients with type 2 diabetes mellitus (DM2). Importantly, recent large randomised controlled trials have demonstrated that many of these agents reduce the occurrence of major adverse cardiovascular events, hospitalisation for heart failure (HF), cardiovascular death and/or progression of chronic kidney disease (CKD), regardless of the presence or absence of DM2 [1-9]. These findings, combined with the beneficial overall safety profile, make SGLT2 inhibitors an interesting therapeutic approach for the cardiologist. However, despite accumulating data supporting this new class of therapy, cardiologists infrequently prescribe SGLT2 inhibitors, potentially due to a lack of familiarity with their use and concern about prescribing them in combination with other glucose-lowering medications, such as insulin therapy. A relatively simple flow chart can be designed to give most cardiologists more confidence and the assurance they are not going to do harm.

In this article, we provide an up-to-date practical guide for the Dutch cardiologist, highlighting important elements for treatment initiation, dosing, anticipated adverse events and barriers, based on expert opinion and real-world experience in patients with DM2 in the Meander Medical Centre in Amersfoort, the Netherlands. It includes a simple algorithm showing how to initiate SGLT2 inhibitor treatment safely, while considering the consequence of the glucosuric effects of these inhibitors for the individual patient.

\section{Mechanism of action}

The SGLT2 receptor is a sodium-glucose cotransporter located in the proximal tubule of the nephron that is responsible for approximately $90 \%$ of urinary glucose reabsorption. Inhibition of this receptor results in lower blood glucose levels through induction of glucosuria [10]. This effect is more pronounced in the setting of hyperglycaemia, when significant amounts of glucose are filtered into the urine. Glucosuria diminishes significantly as blood glucose levels normalise. Furthermore, as the estimated glomerular filtration rate (eGFR) decreases, the effects of inhibiting the SGLT2 receptor on blood glucose levels are smaller. The risk of hypoglycaemia in patients on an SGLT2 inhibitor is therefore extremely low, unless this agent is taken concomitantly with insulin or sulfonylureas.

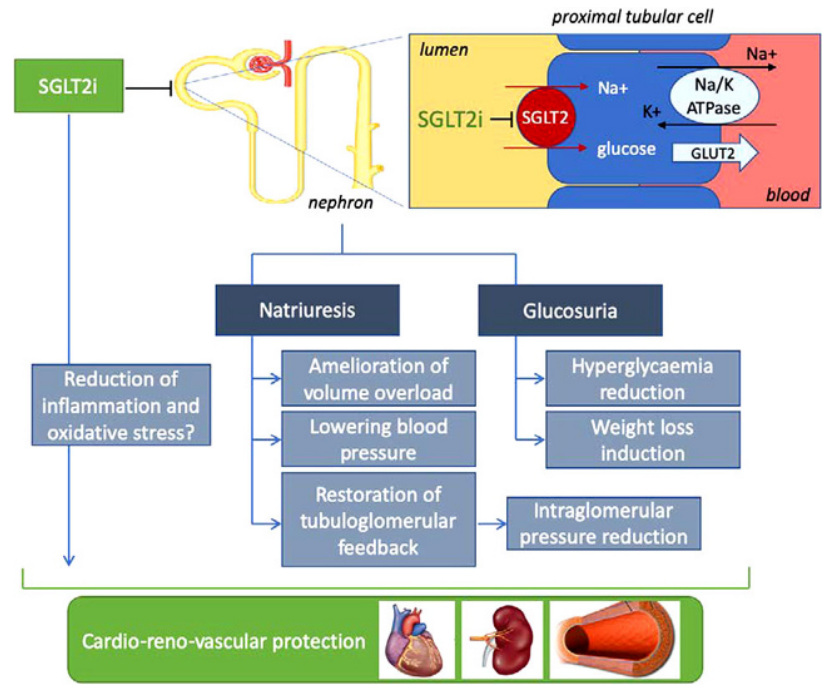

Fig. 1 Mechanism of effects of sodium-glucose cotransporter 2 inhibitor (SGLT2i). GLUT2 glucose transporter 2

Beyond their effect on blood glucose levels, SGLT2 inhibitors also cause diuretic and possibly natriuretic effects, promote weight loss and lower systolic blood pressure (Fig. 1; [10]). Although the mechanism of effects of SGLT2 inhibitors have not been fully elucidated, it is largely independent of lowering $\mathrm{HbA}_{\mathrm{lc}}$ levels, and a number of putative mechanisms have been proposed [10].

\section{Major adverse cardiovascular events}

Large randomised controlled trials in patients with DM2 have demonstrated that many of these agents reduce major adverse cardiovascular event endpoints in patients with established atherosclerotic cardiovascular disease and/or CKD and reduce the risk of HF hospitalisations (see Table S1 in the Electronic Supplementary Material) [1-9]. These benefits may be similar for agents within this class, although there are differences that are likely to reflect the patient populations enrolled in the trials [1-8].

SGLT2 inhibitors have moderate effects (risk reduction $\sim 14 \%$ ) on atherosclerotic major adverse cardiovascular events that seem confined to patients with established atherosclerotic cardiovascular disease or CKD (eGFR $<60 \mathrm{~mL} / \mathrm{min}$ per $1.73 \mathrm{~m}^{2}$ ) [11].

\section{Heart-failure events}

At first, the benefit of reducing the number of HF hospitalisations in SGLT2 inhibitor trials [1-6] primarily reflected prevention of symptomatic HF in DM2 patients at high risk, as approximately $90 \%$ did not have $\mathrm{HF}$ at baseline (and those who did, were not well characterised). The effects of SGLT2 inhibitors on HF hospitalisation appeared to be remarkably consistent across the class (approximately a 30\% reduction in 
hospitalisation for HF; see Table S1 in the Electronic Supplementary Material).

More recently, the benefits of an SGLT2 inhibitor in treating established HF were demonstrated in the DAPA-HF (Study to Evaluate the Effect of Dapagliflozin on the Incidence of Worsening HF or Cardiovascular Death in Patients with Chronic HF) and the EMPEROR-Reduced (Cardiovascular and Renal Outcomes with Empagliflozin in Heart Failure) trial $[7,8]$. Both studies enrolled patients with HF failure with reduced ejection fraction (HFrEF) with and without DM who were receiving appropriate background treatments for HF. A recent meta-analysis of these two trials reported that in patients with a broad spectrum of HFrEF severity, SGLT2 inhibition with empagliflozin or dapagliflozin, on top of guideline-directed medical therapy, reduced all-cause and cardiovascular death, HF hospitalisations and serious adverse renal outcomes, without heterogeneity between the two trials [12].

The pooled treatment effects showed consistent benefits for subgroups based on age, sex, presence of DM, baseline eGFR or background treatment with an angiotensin receptor-neprilysin inhibitor, but suggested treatment-by-subgroup interactions for subgroups based on the New York Heart Association (NYHA) functional class and possibly race. The pooled hazard ratio for patients in NYHA class II $(0.67,95 \%$ confidence interval (CI) 0.59-0.76) differed from that for patients in class III-IV $(0.87,0.75-1.01)$. Beneficial effects on symptoms, functional status and quality of life in patients with HFrEF were also reported. Additional trials with various agents in patients with HF with preserved ejection fraction are ongoing.

\section{Renal events}

In addition, consistent reductions in the secondary outcome of risk of kidney disease progression were seen with all agents in the cardiovascular outcome trials, although the number of 'hard' renal events (e.g. progression to end-stage renal disease and renal death) was small. The CREDENCE (Evaluation of the Effects of Canagliflozin on Renal and Cardiovascular Outcomes in Participants with Diabetic Nephropathy) trial [5] and DAPA-CKD (Dapagliflozin in Patients with Chronic Kidney Disease) trial [6] - both dedicated renal outcome trials involving the SGLT2 inhibitor class-reported that both canagliflozin and dapagliflozin significantly reduced the composite of a sustained eGFR decline $\geq 50 \%$, end-stage kidney disease or death from renal or cardiovascular causes. The DAPA-CKD trial demonstrated that these beneficial renal effects were similar in participants with and without DM2.

Mechanisms to explain these observations may include activation of tubuloglomerular feedback, reduction in glomerular hypertension, containment of hyperfiltration injury, reduction of kidney hypoxia and possible effects on sodium-hydrogen exchange $[10,13]$.

\section{Other adverse events}

An increased risk of genital mycotic infections (mostly candida vaginitis in women, balanitis in men) has been seen with all SGLT2 inhibitors [11]. These infections are usually not harmful and tend to resolve after a brief course of antifungal therapy, although careful education and monitoring are imperative in patients considered to be at high risk of infectious complications. Rare reports of necrotising fasciitis of the perineum (Fournier's fasciitis) led the Food and Drug Administration (FDA) to request the addition of a warning to the SGLT2 inhibitor prescribing instructions; whether these very rare but serious infections are causally related to SGLT2 inhibitor therapy remains unclear [14].

An increased risk of amputations and fractures was observed in one trial during treatment with canagliflozin; however, this phenomenon was not seen in other trials or in the other canagliflozin trial (CREDENCE). The clinical importance of any possible increase in amputation risk is also unknown, but caution is suggested in those with a history of peripheral artery disease and/or lower extremity diabetic ulcers. A recent meta-analysis indicated that SGLT2 inhibitors do not increase the risk of bone fracture in patients with DM2 compared with placebo [15]. There was a small risk of diabetic ketoacidosis (DKA), which may present itself in the absence of significant hyperglycaemia-often called 'euglycaemic DKA' [16]. Patients with DM2 who have progressed to an insulin-deficient state may develop euglycaemic DKA as a result of SGLT2 inhibitor therapy. The risk of developing DKA was almost two times higher in patients with DM2 taking SGLT2 inhibitors than in those taking placebo $(2.20,95 \%$ CI $1.25-3.87)$, but the event rates were low (<1 per 1000 patient-years) [11].

A recent meta-analysis showed no increased risk of DKA in patients with DM2 taking an SGLT2 inhibitor compared with placebo [17]. In general, DKA predominantly renders a significant problem in DM1 patients who are treated with SGLT2 inhibition. However, it should be emphasised that DKA can occur in patients with DM2 and awareness of this complication is important. Lastly, the osmotic diuretic effect of SGLT2 inhibitors could lead to volume depletion and electrolyte imbalances, especially in patients with malnutrition and/or low intake.

\section{National and international guidelines}

The 2019 Clinical Practice Guidelines by the European Society of Cardiology (ESC) on DM recommend either SGLT2 inhibitors or glucagon-like peptide-1 receptor agonists (GLP-1 RAs) in patients with DM2 and established atherosclerotic cardiovascular disease or in case 
of very high/high cardiovascular risk (e.g. $\geq 3$ major risk factors or DM duration $\geq 10$ years), to reduce cardiovascular events [18]. In addition, SGLT2 inhibitors are recommended to lower risk of HF hospitalisation if eGFR $>30 \mathrm{~mL} / \mathrm{min}$ per $1.73 \mathrm{~m}^{2}$.

The 2019 version of 'Management of Hyperglycemia in Type 2 Diabetes', a consensus report by the American Diabetes Association and the European Association for the Study of Diabetes, offers more direction on when to prescribe SGLT2 inhibitors or GLP-1 RAs in patients with DM2 at high or very high cardiovascular risk [19]. The level of evidence for benefit of SGLT2 inhibitors is greatest for patients with or without established atherosclerotic cardiovascular disease but with HFrEF (left ventricular ejection fraction (LVEF) $<40 \%$ ) or CKD (eGFR 30-60 mL/min per $1.73 \mathrm{~m}^{2}$ or urine albumin:creatinine ratio (UACR) $>30 \mathrm{mg} / \mathrm{g}$, particularly when UACR $\geq 300 \mathrm{mg} / \mathrm{g}$ ).

Most guidelines do not address patients without DM2. The Canadian Cardiovascular Society/Canadian Heart Failure Society's Heart Failure Guidelines are among the first to recommend that SGLT2 inhibitors be prescribed in patients with HFrEF (LVEF < 40\%) and without concomitant DM, to improve symptoms and quality of life and to reduce the risk of hospitalisation and cardiovascular mortality [20]. The in 2021 updated version of the expert consensus decision pathway by the American College of Cardiology also recommends SGLT2 inhibitor therapy in patients with HFrEF with or without DM2 [21]. An update of the ESC guideline is expected next year. Cardiologists should consider adding an SGLT2 inhibitor in patients with HFrEF and without DM2; however, our real-world evidence is based on patients with DM2.

Dutch guidelines on DM, CKD and HF are currently being updated. The Dutch Diabetic Nephropathy guideline recommends SGLT2 inhibitor therapy in two patient groups: (1) eGFR $30-60 \mathrm{~mL} / \mathrm{min}$ per $1.73 \mathrm{~m}^{2}$ and UACR $>3 \mathrm{mg} / \mathrm{mmol}$, and (2) eGFR $\geq 60 \mathrm{~mL} / \mathrm{min}$ per $1.73 \mathrm{~m}^{2}$ and UACR $>30 \mathrm{mg} / \mathrm{mmol}$ [22].

\section{Algorithm for SGLT2 inhibitor treatment initiation}

SGLT2 inhibitor therapy can be considered for patients with the following characteristics:

- DM2 and a very high cardiovascular risk:

1. Established atherosclerotic cardiovascular disease: prior myocardial infarction, ischaemic stroke, unstable angina with electrocardiographic changes, myocardial ischaemia on imaging or stress test, or revascularisation of coronary, carotid, or peripheral arteries.
2. Chronic kidney disease ${ }^{1}$ (eGFR 30-60 mL/min per $1.73 \mathrm{~m}^{2}$ and UACR $>3 \mathrm{mg} / \mathrm{mmol}$ or eGFR $\geq 60 \mathrm{~mL} / \mathrm{min}$ per $1.73 \mathrm{~m}^{2}$ and UACR $>30 \mathrm{mg} / \mathrm{mmol}$ ). - $\operatorname{HFrEF}(\mathrm{LVEF}<40 \%)$

Although the FDA-approved cardiovascular indications are different, SGLT2 inhibitors appear to have broadly similar cardiovascular and renal benefits (see Table S1 in the Electronic Supplementary Material). A summary of the doses, indications, contraindications and adverse effects of SGLT2 inhibitors is shown in Table S2 (see Electronic Supplementary Material).

Mostly, SGLT2 inhibitor treatment can be initiated safely by a cardiologist (Fig. 2). However, the following recommendations should be considered:

- The patient's diabetes care provider (general practitioner, internist, nephrologist) should always be notified with a letter stating the clinical importance of SGLT2 inhibitors, any changes in diabetes medication, the possibility of adverse events (with specific attention to DKA) and the method of follow-up.

- SGLT2 inhibitors should not be prescribed in patients with DM1. If the type of DM has not be established, we advise to consult an internist, who may suggest diabetes autoantibody tests.

- Prescribers should be aware of precipitating factors of ketoacidosis (e.g. insulin cessation, prednisone administration, dehydration, hyperglycaemia, low carbohydrate intake/low food intake, excessive alcohol use). They should educate patients about the signs or symptoms of ketoacidosis (nausea, vomiting, abdominal pain, weakness) and instruct patients to discontinue SGLT2 inhibitors and seek immediate medical attention in case of such complaints. If there is (a low) clinical suspicion of DKA, we recommend consulting an internist for further advice.

- If $\mathrm{HbA}_{\mathrm{lc}} \geq 64 \mathrm{mmol} / \mathrm{mol}$ or the patient is treated with comprehensive lifestyle management only or in combination with glucose-lowering therapy with a low risk of hypoglycaemia (metformin, dipeptidyl peptidase-4 inhibitors, GLP-1 RAs), SGLT2 inhibitor treatment can be initiated safely without modifications.

- If $\mathrm{HbA}_{\mathrm{lc}}<64 \mathrm{mmol} / \mathrm{mol}$ and the patient is treated with glucose-lowering therapy with an increased risk of hypoglycaemia (i.e. sulfonylureas, insulin), SGLT2 inhibitor can only be initiated after adjustment of these glucose-lowering agents:

- If patient is on a sulfonylurea drug but not on insulin, discontinue this therapy if patient is on:

a) gliclazide $\leq 80 \mathrm{mg}$ once daily

b) glimepiride $\leq 2 \mathrm{mg}$ once daily

${ }^{1}$ Summary of product characteristics states that SGLT2 inhibitor treatment should not be initiated in patients with eGFR $<60 \mathrm{~mL} / \mathrm{min}$ per $1.73 \mathrm{~m}^{2}$ because the glycaemic efficacy depends on renal function. This label will be changed as the beneficial cardiovascular effects do not depend on renal function. 




Fig. 2 Flow chart of initiation of sodium-glucose cotransporter 2 (SGLT2) inhibitor treatment. DM2 type 2 diabetes mellitus, ASCVD atherosclerotic cardiovascular disease, eGFR estimated glomerular filtration rate, DM1 type 1 diabetes mellitus, SU sulfonylurea, DPP-4 dipeptidyl peptidase-4, GLP-1 RA glucagon-like peptide-1 receptor agonist. *Dis-

continue sulfonylurea if patient is on gliclazide $\leq 80 \mathrm{mg}$ once daily/glimepiride $\leq 2 \mathrm{mg}$ once daily/tolbutamide $\leq 500 \mathrm{mg}$ twice daily. Otherwise, reduce sulfonylurea dose by $50 \%$. ${ }^{* *}$ If patient is on insulin $\leq 12 \mathrm{lU} /$ day, discontinue insulin. If patient is on insulin $>12 \mathrm{IU}$, reduce every insulin dose by $20 \%$

c) tolbutamide $\leq 500 \mathrm{mg}$ twice daily

Otherwise, reduce sulfonylurea dose by $50 \%$.

- If patient is on insulin but not on a sulfonylurea drug, reduce every insulin dose by $20 \%$. Discontinue insulin when insulin dose $\leq 12 \mathrm{IU}$.

- If patient is on a combination of sulfonylurea and insulin, and:

a) $\mathrm{HbA}_{\mathrm{lc}} \leq 53 \mathrm{mmol} / \mathrm{mol}$ : reduce or discontinue sulfonylurea drug as stated above and discontinue insulin when insulin dose $\leq 12$ IU. If insulin dose $>12 \mathrm{IU}$, reduce insulin dose by $20 \%$. 
b) $\mathrm{HbA}_{1 \mathrm{c}} 54-64 \mathrm{mmol} / \mathrm{mol}$ : reduce or discontinue sulfonylurea drug as stated above or adjust insulin as stated above.

- If there is uncertainty about changing the insulin dose, we recommend consulting an internist for further advice.

- SGLT2 inhibitors increase the risk of genital mycotic infections, polyuria, and potential volume depletion in the context of hyperglycaemia.

- Patients should be educated about the risk of genital mycotic infections and the importance of genital hygiene (e.g. keeping the genital region dry, especially after urinating). In most cases, genital infections will resolve after standard antifungal therapy without discontinuation of the diabetes medication regimen. If necessary, the therapy can be temporarily interrupted.

- It is prudent to educate patients about the signs and symptoms of dehydration (light-headedness, orthostatic hypotension, weakness), which may be more of a concern outside the clinical trial setting, especially in frail patients. Clinical judgement should be used when initiating SGLT2 inhibitor treatment in patients who will be undergoing renin-aldosterone-angiotensin system inhibition therapy (or in whom this dose is up-titrated) if the patient's renal function is impaired. SGLT2 inhibitors should be discontinued in case of acute kidney injury as with other medications such as sulfonylureas, angiotensin converting enzyme inhibitors, diuretics, metformin, angiotensin receptor antagonists and non-steroidal anti-inflammatory drugs.

- Initiation of SGLT2 inhibitor treatment may lead to a transient acute decline of eGFR at week 4 , followed by a period of stable kidney function during long-term follow-up, as was shown in the EMPAREG OUTCOME trial; eGFR gradually declined with placebo [1].

- Follow-up by the diabetes care provider is essential after two weeks if the patient is on insulin and after six weeks if the patient is not taking insulin.

- The clinical importance of any possible increase in amputation risk remains unclear. It is recommended to examine the feet of all patients on foot wounds and diabetic ulcers with even more awareness for this issue in patients with a history of peripheral artery disease and lower extremity diabetic ulcers. If there is clinical uncertainty about the extent of peripheral artery disease, consult a vascular surgeon. Do not start or discontinue SGLT2 inhibitors if foot wounds and/or ulcers are present.

\section{Real world evidence of efficacy of proposed algorithm}

Experience with the proposed algorithm as shown in Fig. 2 has been obtained in an observational prospective cohort study in the Meander Medical Centre in Amersfoort, with the small difference that an eGFR
Table 1 Baseline characteristics of the Meander Medical Center cohort

\begin{tabular}{|c|c|}
\hline Variable & Patients $(N=84)$ \\
\hline \multicolumn{2}{|l|}{ Patient characteristics } \\
\hline Male & $62(74)$ \\
\hline Age, in years & 70 \\
\hline $\mathrm{BMI}$, in $\mathrm{kg} / \mathrm{m}^{2}$ & 29 \\
\hline \multicolumn{2}{|l|}{ Location of SGLT2 inhibitor treatment initiation } \\
\hline Hospital admission & $35(42)$ \\
\hline Outpatient appointment & $49(58)$ \\
\hline \multicolumn{2}{|l|}{ Type of SGLT2 inhibitor } \\
\hline Empagliflozin & $67(80)$ \\
\hline Dapagliflozin & $17(20)$ \\
\hline Cardiovascular disease $^{\mathrm{a}}$ & $84(100)$ \\
\hline Myocardial infarction & $53(63)$ \\
\hline CABG & $27(33)$ \\
\hline Coronary stenosis $>70 \%$ & $73(87)$ \\
\hline Peripheral arterial disease & $12(14)$ \\
\hline Heart failure, type & $20(23)$ \\
\hline - Ischaemic & $13(16)$ \\
\hline - Non-ischaemic & $5(6)$ \\
\hline - Unknown aetiology & $2(2)$ \\
\hline Diabetes mellitus diagnosis & $84(100)$ \\
\hline De novo & $3(4)$ \\
\hline Diabetic treatment (previously) prescribed by GP & $72(86)$ \\
\hline \multicolumn{2}{|l|}{ Diabetic drugs } \\
\hline Metformin & $73(87)$ \\
\hline Sulfonylureas & $35(42)$ \\
\hline DPP-4 inhibitors & $5(6)$ \\
\hline GLP-1 RAs & $4(5)$ \\
\hline Short-acting insulin & $16(19)$ \\
\hline Long-acting insulin & $23(27)$ \\
\hline \multicolumn{2}{|l|}{ Cardiovascular drugs } \\
\hline Beta blockers & $63(75)$ \\
\hline Diuretics & $41(49)$ \\
\hline Calcium channel blockers & $26(31)$ \\
\hline ACE inhibitors & $34(41)$ \\
\hline Angiotensin II receptor blockers & $14(17)$ \\
\hline Alpha blockers & $3(4)$ \\
\hline ARNI & 7 (8) \\
\hline \multicolumn{2}{|l|}{ Anticoagulants } \\
\hline Platelet aggregation inhibitors & $61(73)$ \\
\hline Direct oral anticoagulants & $22(26)$ \\
\hline Vitamin $\mathrm{K}$ antagonists & $10(12)$ \\
\hline \multicolumn{2}{|l|}{ Cholesterol-Iowering drugs } \\
\hline HMG-CoA-reductase inhibitors & $73(87)$ \\
\hline Cholesterol absorption inhibitors & $11(13)$ \\
\hline PCSK9 inhibitors & 2 (2) \\
\hline None & 7 (8) \\
\hline \multicolumn{2}{|c|}{$\begin{array}{l}\text { Data are } n(\%) \text { or mean } \\
B M I \text { body mass index, SGLT2 sodium-glucose cotransporter 2, CABG coro- } \\
\text { nary artery bypass grafting, GP general practitioner, DPP-4 dipeptidyl } \\
\text { peptidase-4, GLP-1 RA glucagon-like peptide-1 receptor agonist, } A C E \text { an- } \\
\text { giotensin-converting-enzyme, } A R N / \text { angiotensin receptor-neprilysin inhibitor, } \\
\text { HMG-CoA 3-hydroxy-3-methyl-glutaryl coenzyme A, PCKS9 proprotein con- } \\
\text { vertase subtilisin/kexin type } 9 \\
\text { a Patient's medical history may include multiple cardiovascular comorbidities }\end{array}$} \\
\hline
\end{tabular}


Table 2 Adverse events in the Meander Medical Center cohort

\begin{tabular}{l|l|}
\hline Adverse events & $n(\%)$ \\
\hline Total & $20(24)$ \\
\hline Urogenital infection & $7(8)$ \\
\hline - Genital & $6(7)$ \\
\hline - Urinary tract & $1(1)$ \\
\hline Pruritus & $4(5)$ \\
\hline Polyuria and polydipsia & $3(4)$ \\
\hline General discomfort & $1(1)$ \\
\hline Exacerbation of heart failure & $1(1)$ \\
\hline Severe obstipation & $1(1)$ \\
\hline Foot amputation & $1(1)$ \\
\hline Mild hypoglycaemia ${ }^{\text {a }}$ & $1(1)$ \\
\hline After permanent discontinuation of SGLT2 inhibitor treatment & $11(13)$ \\
\hline Urogenital infection & $5(6)$ \\
\hline Foot amputation & $1(1)$ \\
\hline Exacerbation of heart failure & $1(1)$ \\
\hline General discomfort & $1(1)$ \\
\hline Patient's wish (not related to adverse events) & $3(4)$ \\
\hline $\begin{array}{l}\text { Data are number ( } n \text { ) of adverse events; \% is percentage in total patient } \\
\text { cohort (N=84) }\end{array}$ & \\
\hline SGLT2 sodium-glucose cotransporter 2 & \\
\hline a Serum glucose level temporarily $<3.9$ mmol/L, no help from others needed
\end{tabular}

cut-off value of $<45 \mathrm{~mL} / \mathrm{min}$ per $1.73 \mathrm{~m}^{2}$ was used previously instead of $<30 \mathrm{~mL} / \mathrm{min}$ per $1.73 \mathrm{~m}^{2}$. We changed the eGFR cut-off value after completion of this study and after publication of the DAPA-CKD and EMPEROR-Reduced trial results, which showed beneficial effects of SGLT2 inhibitor treatment on renal function $[6,8]$.

From 15 November 2019 until 1 November 2020, 84 patients were included and observed for followup. The median follow-up period was 143 days. Baseline characteristics are summarised in Tab. 1. Patients on insulin therapy were seen by the diabetes nurse specialist at the outpatient clinic 1 to 2 weeks after treatment initiation. All patients who started taking an SGLT2 inhibitor, were seen by the internist 6 weeks after initiation.

Based on the algorithm, the cardiologist changed glucose-lowering medication in 19 of the 84 patients (23\%) (16 times sulfonylurea, 3 times long-acting insulin). In one of these patients, the internist further reduced the long-acting insulin dose based on the $\mathrm{HbA}_{\mathrm{lc}}$ level. The long-acting insulin dose was reduced in other 11 cases and discontinued in 3 cases by the internist, again based on $\mathrm{HbA}_{1 c}$ level targets and not due to hypoglycaemic events. Mean $\mathrm{HbA}_{1 \mathrm{c}}$ level reduced from 62 to $57 \mathrm{mmol} / \mathrm{mol}$. Mean eGFR decreased from 73 to $69 \mathrm{~mL} / \mathrm{min}$ per $1.73 \mathrm{~m}^{2}$, which is expected in the initial phase of SGLT2 inhibitor treatment.

In total, 20 adverse events (24\%) were reported, including 7 urogenital infections (Tab. 2). Adverse events led to permanent discontinuation of an SGLT2 inhibitor in 8 patients. One patient underwent an am- putation of the third digit of the right foot 2.5 weeks after initiation of SGLT2 inhibitor treatment. Neither the presence of foot wounds or diabetic ulcers nor patient's symptoms were mentioned in the patient's file upon treatment initiation. In retrospect, this patient did have newly diagnosed peripheral artery disease after he started taking the SGLT2 inhibitor. This emphasises the importance of actively asking patients about the presence of any foot wounds or complaints before initiating SGLT2 inhibitor treatment. Another adverse advent was an HF exacerbation after diuretic dose reduction subsequent to SGLT2 inhibitor treatment initiation. Caution is warranted when the diuretic dose is reduced upon initiating SGLT2 inhibitor treatment.

A 63-year-old, obese male with a medical history of atrial fibrillation and coronary artery bypass grafting died in his sleep for unknown reasons and did not have any prodromal symptoms 6 months after SGLT2 inhibitor treatment initiation. Sudden death is not a known adverse effect of SGLT2 inhibitors [1-9].

Six patients were lost to follow-up early on, because they wished to return to their general practitioner for diabetic care.

Statistical analysis of our observational non-randomised data was not possible and conclusions based on statistically significant differences could therefore not be drawn. However, our results do show preliminary safety in this population, and our study can serve as a valuable experience for cardiologists wanting to prescribe SGLT2 inhibitors in patients with DM2.

\section{Conclusion}

This article provided a practical guide for cardiologists on initiating and monitoring of SGLT2 inhibitor treatment. Although we intended to facilitate clinical decision-making, the information provided in this article should complement, rather than supersede, good clinical judgement. Study data from our hospital suggest that using the algorithm presented was safe and gave cardiologists enough confidence and the assurance they were not going to do harm. It is important to strive for good multidisciplinary cooperation, not only between the departments of Cardiology and Internal medicine, but also with general practitioners and pharmacists.

We anticipate that our algorithm changes as new evidence emerges, but the goal is still to safely improve cardiovascular outcomes in patients with DM2 at very high risk of atherosclerotic disease.

Acknowledgements The authors would like to thank Judith Brouwer, pharmacist at the Meander Medical Centre, for assistance during the cohort study at this hospital.

Funding M.L. Handoko is supported by the Dutch Heart Foundation (Senior Clinical Scientist grant no. 2020T058). 


\section{Advertisement placed here.}



Houten 2021 


\section{Advertisement placed here.}

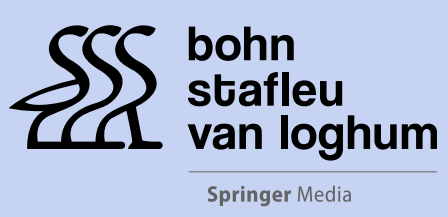

Houten 2021 


\section{Declarations}

Conflict of interest K. Zwart has received a small grant for writing an AstraZeneca educational programme. S. Velthuis has received speaker's fees from Boehringer Ingelheim and AstraZeneca. A. Mosterd has received a small grant for writing an AstraZeneca educational programme. However, he does not accept personal fees from pharmaceutical companies. Therefore, these fees will be donated to research foundations. D.H. van Raalte serves on advisory boards for Boehringer Ingelheim, Eli Lilly Alliance, Sanofi and Merck Sharp \& Dohme (MSD) and has received research grants from AstraZeneca, Boehringer Ingelheim, Eli Lilly, Sanofi and MSD. All honoraria were paid to his employer. M.L. Handoko serves on advisory boards for Novartis, Boehringer Ingelheim, Vifor Pharma, AstraZeneca, Bayer, MSD and Quin. He has also received education and research grants from Novartis, Boehringer Ingelheim and Vifor Pharma, which were paid to his employer. P.C. Oldenburg-Ligtenberg has served on an advisory board for Boehringer Ingelheim. She has also received a small grant for writing an AstraZeneca educational programme and a speaker's fee from Boehringer Ingelheim. Y.V. Polyukhovych, L. Smidt, E.H. Serné and P.J.M. Elders declare that they have no competing interests.

Open Access This article is licensed under a Creative Commons Attribution 4.0 International License, which permits use, sharing, adaptation, distribution and reproduction in any medium or format, as long as you give appropriate credit to the original author(s) and the source, provide a link to the Creative Commons licence, and indicate if changes were made. The images or other third party material in this article are included in the article's Creative Commons licence, unless indicated otherwise in a credit line to the material. If material is not included in the article's Creative Commons licence and your intended use is not permitted by statutory regulation or exceeds the permitted use, you will need to obtain permission directly from the copyright holder. To view a copy of this licence, visit http://creativecommons.org/licenses/by/4.0/.

\section{References}

1. Zinman B, Wanner C, Lachin JM, et al. Empagliflozin, cardiovascular outcomes, and mortality in type 2 diabetes. NEngl J Med. 2015;373:2117-28.

2. Perkovic V, Jardine MJ, Neal B, et al. Canagliflozin and renal outcomesin type 2 diabetes and nephropathy. NEnglJ Med. 2019;380:2295-306.

3. Neal B, Perkovic V, Mahaffey KW, et al. Canagliflozin and cardiovascular and renal events in type 2 diabetes. $\mathrm{N}$ Engl J Med. 2017;377:644-57.

4. Wiviott SD, Raz I, Bonaca MP, et al. Dapagliflozin and cardiovascular outcomes in type 2 diabetes. N Engl J Med. 2019;380:347-57.

5. Heerspink HJ, Stefánsson BV, Correa-Rotter R, et al. Dapagliflozin in patients with chronic kidney disease. NEngl J Med. 2020;383:1436-46.

6. McMurray JJ, Solomon SD, Inzucchi SE, et al. Dapagliflozin in patients with heart failure and reduced ejection fraction. NEngl J Med. 2019;381:1995-2008.

7. Packer M, Anker SD, Butler J, et al. Cardiovascular and renal outcomes with empagliflozin in heart failure. NEngl J Med. 2020;383:1413-24.

8. Cannon CP, Pratley R, Dagogo-Jack S, et al. Cardiovascular outcomes with ertugliflozin in type 2 diabetes. NEngl J Med. 2020;202:1425-35.
9. Bhatt DL, Szarek M, Steg PG, et al. Sotagliflozin in patients with diabetes and recent worsening heart failure. N Engl J Med. 2021;384:117-28.

10. Zelniker TA, Braunwald E. Mechanisms of cardiorenal effects of sodium-glucose cotransporter 2 inhibitors: JACC state-of-the-art review. J Am Coll Cardiol. 2020;202:422-34.

11. Zelniker TA, Wiviott SD, Raz I, et al. SGLT2 inhibitors for primary and secondary prevention of cardiovascular and renal outcomes in type 2 diabetes: a systematic review and meta-analysis of cardiovascular outcome trials. Lancet. 2019;393:31-9.

12. Zannad F, Ferreira JP, Pocock SJ, et al. SGLT2 inhibitors in patients with heart failure with reduced ejection fraction: a meta-analysis of the EMPEROR-reduced and DAPA-HF trials. Lancet. 2020;396:819-29.

13. van Bommel EJ, Muskier MH, van Baar MJ, et al. The renal hemodynamic effects of the SGLT2 inhibitor dapagliflozin are caused by post-glomerular vasodilatation rather than pre-glomerular vasoconstriction in metformin-treated patients with type 2 diabetes in the randomized, double-blind RED trial. Kidney Int. 2020;97:202-12.

14. Bersoff-Matcha SJ, Charberlain C, Cao C, et al. Fournier gangrene associated with sodium-glucose cotransporter-2 inhibitors: a review of spontaneous postmarketing cases. Ann Intern Med. 2019;170:764-9.

15. Cheng L, Li YY, Hu W, et al. Risk of bone fracture associated with sodium-glucose cotransporter-2 inhibitor treatment: a meta-analysis of randomized controlled trials. Diabetes Metab. 2019;45:436-45.

16. Rosenstock J, Ferrannini E. Euglycemic diabetic ketoacidosis: a predictable, detectable, and preventable safety concern with SGLT2 inhibitors. Diabetes Care. 2015;38:1638-42.

17. Palmer SC, Tendal B, Mustafa RA, et al. Sodium-glucose cotransporter protein-2 (SGLT-2) inhibitors and glucagonlike peptide-1 (GLP-1) receptor agonists for type 2 diabetes: systematic review and network meta-analysis of randomised controlled trials. BMJ. 2021;372:m4573.

18. Cosentino F, Grant PJ, Aboyans V, et al. 2019 ESC guidelines on diabetes, pre-diabetes, and cardiovascular diseases developed in collaboration with the EASD: the Task Force for diabetes, pre-diabetes, and cardiovascular diseases of the European Society of Cardiology (ESC) and the European Association for the Study of Diabetes (EASD). Eur Heart J. 2020;41:255-323.

19. Buse JB, Wexler DJ, Tsapas A, et al. 2019 Update to: management of hyperglycemiain type 2 diabetes, 2018. Aconsensus report by the American Diabetes Association (ADA) and the European Association for the Study of Diabetes (EASD). Diabetes Care. 2020;43:487-93.

20. O'Meara E, McDonald M, Chan M, et al. CCS/CHFS heart failure guidelines: clinical trial update on functional mitral regurgitation, SGLT2 inhibitors, ARNI in HFpEF, and tafamidis in amyloidosis. Can JCardiol. 2020;36:159-69.

21. Maddox TM, Januzzi JL, Allen LA, et al. 2021 Update to the 2017 ACC expert consensus decision pathway for optimization of heart failure treatment: answers to 10 pivotal issues about heart failure with reduced ejection fraction. J Am Coll Cardiol. 2021;77:772-810.

22. Dutch diabetic nefropathy guideline. https://richtlijnen database.nl/richtlijn/diabetische_nefropathie/nieuwe_ glucoseverlagende_middelen_bij_diabetische_nefropa thie/sglt-2-remmers_bij_diabetische_nefropathie.html. Accessed 25 Nov 2020. 